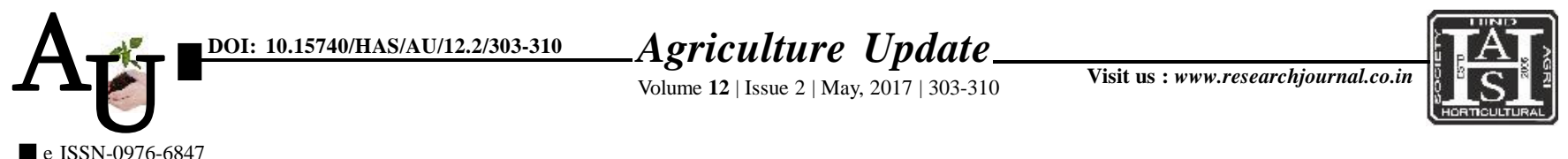

\title{
Research Article: Effect of degree of attributes on rate of adoption of farm technology in desert tract of Rajasthan
}

\author{
口.S. BAGENIA, S.R. KUMAWAT AND DEEPAK CHATURVEDI
}

Article Chronicle : Received : 08.03.2017;

Received : 09.04.2017; Accepted : 23.04.2017

KEY WoRds : Commercialization index, Cost effectiveness, Erratic rainfall, Food security, Innovative institute, Peak season

Author for correspondence :

P.S. BAGENIA

Department of

Extension Education, College of Agriculture (S.K.N.A.U.), BHARATPUR (RAJASTHAN) INDIA

See end of the article for authors' affiliations
SUMMARY : This study was conducted in the desert tract of Rajasthan of during the year 2012-13. To know the causes and motives behind the adoption or non-adoption of the technology base among our diverse farming community. The result revealed that accessibility and cost effectiveness and among the potential causes of non-adoption of recommended production technologies and that very encouraging level of the factors viz., attitude towards innovative farm institute commercialization index and surplus income leads to a high rates of adoption. Out of 160 farmers 42.62 per cent were found to have high rate of technology adoption in various crops whereas, 34.08 and 23.30 per cent farmers had adopted medium and low level of technology. Result highlighted that technology adoption level was highest in fertilizer technology upto 59.17 per cent and only farmers used it upto low level in fertilizer and number of irrigation, respectively. It was also found that maximum farmers were having very encouraging (favorable) levels of attitude towards, Innovative farm, surplus income, commercialization, index farm size, economic information and extension linkage. Had obtained high level of technology. The results further indicated that 'lack of knowledge about chemical weed control', 'weed control through weedicides is technically complex method', 'lack of knowledge about chemical and quantity in plant protection measures and for seed treatment', labour charges costly were the main constraints as perceived by the respondents in adoption of farm technology.

How to cite this article : Bagenia, P.S., Kumawat, S.R. and Chaturvedi, Deepak (2017). Effect of degree of attributes on rate of adoption of farm technology in desert tract of Rajasthan. Agric. Update, 12(2): 303-310; DOI : 10.15740/HAS/AU/12.2/303-310. 